\title{
A test of trophic cascade theory: fish and benthic assemblages across a predator density gradient on coral reefs
}

\author{
Jordan M. Casey ${ }^{1} \cdot$ Andrew H. Baird $^{1} \cdot$ Simon J. Brandl ${ }^{2} \cdot$ Mia O. Hoogenboom $^{1,3}$ • \\ Justin R. Rizzari ${ }^{1,3} \cdot$ Ashley J. Frisch ${ }^{1,4} \cdot$ Christopher E. Mirbach $^{3}$. \\ Sean R. Connolly ${ }^{1,3}$
}

Received: 31 October 2015 / Accepted: 6 October 2016 / Published online: 15 October 2016

(C) Springer-Verlag Berlin Heidelberg 2016

\begin{abstract}
Removal of predators is often hypothesized to alter community structure through trophic cascades. However, despite recent advances in our understanding of trophic cascades, evidence is often circumstantial on coral reefs because fishing pressure frequently co-varies with other anthropogenic effects, such as fishing for herbivorous fishes and changes in water quality due to pollution. Australia's outer Great Barrier Reef (GBR) has experienced fishing-induced declines of apex predators and mesopredators, but pollution and targeting of herbivorous fishes are minimal. Here, we quantify fish and benthic assemblages across a fishing-induced predator density gradient on the outer GBR, including apex predators and mesopredators to herbivores and benthic assemblages, to test for evidence of trophic cascades and alternative hypotheses to trophic cascade theory. Using structural equation models, we found
\end{abstract}

Communicated by Joel Trexler.

Electronic supplementary material The online version of this article (doi:10.1007/s00442-016-3753-8) contains supplementary material, which is available to authorized users.

Jordan M. Casey

jcasey508@gmail.com

1 Australian Research Council Centre of Excellence for Coral Reef Studies, James Cook University, Townsville, QLD 4811, Australia

2 Tennenbaum Marine Observatories Network, Smithsonian Environmental Research Centre, 647 Contees Wharf Road, Edgewater, MD 21037, USA

3 Marine Biology and Aquaculture, College of Science and Engineering, James Cook University, Townsville, QLD 4811, Australia

4 Reef HQ, Great Barrier Reef Marine Park Authority, 2-68 Flinders Street, Townsville, QLD 4810, Australia no cascading effects from apex predators to lower trophic levels: a loss of apex predators did not lead to higher levels of mesopredators, and this did not suppress mobile herbivores and drive algal proliferation. Likewise, we found no effects of mesopredators on lower trophic levels: a decline of mesopredators was not associated with higher abundances of algae-farming damselfishes and algae-dominated reefs. These findings indicate that top-down forces on coral reefs are weak, at least on the outer GBR. We conclude that predator-mediated trophic cascades are probably the exception rather than the rule in complex ecosystems such as the outer GBR.

Keywords Community ecology $\cdot$ Fishing $\cdot$ Herbivory · Marine protected areas $\cdot$ Top-down effects

\section{Introduction}

Trophic cascades occur in both terrestrial and aquatic systems (Pace et al. 1999) and result from reciprocal predator-prey interactions, which cause alternating increases and decreases in the biomass of trophic levels throughout a food web (Polis et al. 2000). For instance, in a simple three-tiered system that includes predators, herbivores, and primary producers, the loss of predators can release herbivore populations from predation-related mortality and subsequently suppress the abundance and biomass of primary producers (Pace et al. 1999). This 'linear' theory of simple stepwise effects has been challenged on the basis that it oversimplifies complex species interactions within food webs and ignores other factors, such as omnivory, ontogenetic changes in diet, and nutrient availability, which may affect food web dynamics (Polis and Strong 1996). 
Further analysis of trophic cascade patterns led to the discrimination between species-level and community-level cascades (Polis et al. 2000). Species-level cascades are trophic cascades that occur in a subset of a community, affecting only a few primary producers. For example, the exclusion of birds from bilberry shrubs caused an increase in insect larval density followed by a decline in bilberry (Polis et al. 2000). Conversely, community-level cascades affect the biomass of an entire trophic level in the aggregate (Polis et al. 2000). More recently, meta-analyses of trophic cascades across different ecosystems have defined the characteristics and drivers of strong trophic cascades. For instance, Shurin et al. (2002) found that trophic cascades are strongest in marine benthic communities and weakest in marine plankton and grasslands. Several factors have been identified as the drivers of such strong trophic cascades, including high system productivity (based on plant production to biomass ratios; Shurin and Seabloom 2005), distinct metabolic requirements of organisms within a system (namely, endothermic vertebrate predators and invertebrate herbivores; Borer et al. 2005), and high nutritional quality of primary producers (Cebrian et al. 2009). In an applied context, trophic cascade theory is widely used across the ecological literature to identify impacts of anthropogenic disturbances to predators on the biomass of primary producers. For instance, in Yellowstone National Park, the reintroduction of wolves has limited elk foraging behaviour, which has promoted the successful re-establishment of aspen in the mesic upland steppe and riparian habitats (Ripple et al. 2001). In addition, due to the overexploitation of oceanic fishes in western Alaska, killer whales have overhunted sea otters, allowing high densities of sea urchins to flourish, which caused severe deforestation of kelp forests (Estes et al. 1998).

In marine environments, substantial declines in the abundance and biomass of predators have occurred worldwide (Pauly et al. 1998; Jackson et al. 2001). The depletion of predators has been reported to cause trophic cascades in various marine ecosystems (Dulvy et al. 2004; Baum and Worm 2009). For example, overfishing of predatory fishes in the Baltic Sea led to an increase in small-bodied predatory fish, followed by a reduction of gastropod grazers, and ultimately, this contributed to macroalgae blooms (Eriksson et al. 2009). Depletion of predators in marine systems can also indirectly cause cascading effects, for instance by modifying the behaviour of mesopredators and herbivores, thus altering lower level ecological interactions (Byrnes et al. 2006; Madin et al. 2010).

On coral reefs, trophic cascades have been hypothesized to occur when overfishing apex predators triggers an increase in mesopredators, causing subsequent declines in herbivorous fishes via mesopredator release (Ritchie and Johnson 2009). Following declines in herbivorous fishes, macroalgae and turf algae cover increase, which can reduce the cover of coral (Rasher et al. 2013) and crustose coralline algae (CCA) abundance (O'Leary and McClanahan 2010) via competition effects. Alternatively, direct overfishing of mesopredators may result in increases in territorial or planktivorous damselfishes due to prey release (Graham et al. 2003; Ceccarelli et al. 2006). Coral reef mesopredator density has been negatively correlated with the abundance of territorial damselfishes (Vermeij et al. 2015), and this can potentially influence benthic composition since territorial damselfishes propagate thick turf algae, which lowers the abundance of juvenile corals (Casey et al. 2015), and have been linked to increases in the prevalence of coral disease (Casey et al. 2014; Vermeij et al. 2015).

To date, very little unambiguous empirical evidence of trophic cascades in coral reef systems is available (Ferretti et al. 2010). Several properties of coral reef food webs may weaken or inhibit trophic cascades and explain the conflicting results of different studies. Reef species have a high degree of omnivory and trophic versatility (Thompson et al. 2007), and reefs are relatively open systems, which permit trophic interactions with the pelagic environment (Polis et al. 1997). Consequently, coral reefs may deviate from the linear trophic chains that classical trophic cascade theory assumes. Moreover, primary productivity, consumption rates, and the dispersal of larvae or predators among reefs may mediate top-down control at the reef scale (Stier et al. 2014). Further, experimental manipulations are not feasible across whole reef and large spatial scales, so coral reef ecologists instead must utilize natural experiments. The density and biomass of different trophic groups across management zones are the central components of these studies, and they focus on the topdown impacts of predators on lower trophic levels (Friedlander and DeMartini 2002; Sandin et al. 2008; Ruppert et al. 2013; Emslie et al. 2015). While overfishing has been linked to apex predator declines, it has also resulted in a lower biomass of mesopredators and herbivores (the Hawaiian Islands; Friedlander and DeMartini 2002), the domination of planktivorous fishes and algae (the Northern Line Islands; Sandin et al. 2008), and a mesopredator release resulting in lower levels of herbivorous fishes and higher algal cover (northwest Australia; Ruppert et al. 2013). However, in these systems, predator fishing gradients co-vary with other anthropogenic effects, such as fishing for herbivorous fishes and changes in water quality due to pollution and runoff. Here, we seek to reduce the potentially confounding influence of such factors by investigating the repercussions of predator removal on coral reef fishes and benthic composition across a spatially dispersed predator density gradient that is largely independent of other confounding factors (i.e. removal of other trophic levels and pollution). 
The Great Barrier Reef (GBR), Australia, is one of the world's largest and best-protected reef systems (Russ et al. 2008). The implementation of strictly enforced marine protected areas in the GBR conserves high abundances of apex predators (Robbins et al. 2006) and effectively increases mesopredator density and biomass (McCook et al. 2010; Emslie et al. 2015). Even so, the GBR hosts an extensive line-fishery, which is comprised of hundreds of commercial ships and thousands of recreational vessels (Frisch et al. 2014). As a result, there are strong gradients in the density of reef sharks and targeted mesopredators across fished and protected management zones (Robbins et al. 2006; Russ et al. 2008). Two of the most abundant apex predators, the grey reef shark (Carcharhinus amblyrhynchos) and whitetip reef shark (Triaenodon obesus) have been depleted in some areas (Robbins et al. 2006), with grey reef sharks eight to thirty times more abundant in no-entry reefs versus fished reefs and whitetip reef sharks three to four times more abundant in no-entry reefs versus fished reefs (McCook et al. 2010). Further, there is an $82 \%$ higher biomass of targeted mesopredators such as coral trout (Plectropomus spp.) in offshore marine protected areas compared to fished areas (Russ et al. 2008; Emslie et al. 2015). However, there is no evidence of strong top-down effects from predatory fishes to mobile herbivorous fishes on the GBR (Rizzari et al. 2015). Nonetheless, previous studies have not quantified the direct and/or indirect links between predators and benthic composition (corals versus algae), nor have they investigated the role of small-bodied territorial damselfishes in controlling benthic composition. Unlike many other coral reef regions, fishers on the GBR target apex predators and mesopredators almost exclusively; there are negligible fishing impacts on herbivorous fishes (Frisch et al. 2008; Taylor et al. 2012), and the effects of the coral harvest fishery are also negligible (Harriott 2001). Thus, gains or losses of herbivorous fishes and coral cover along gradients of fishing pressure can be attributed to top-down effects rather than direct depletion by fishing or harvesting. Of equal importance, pollution and runoff are exceptionally low on the outer reefs of the GBR (Alongi and McKinnon 2005). In this context, the outer GBR provides an ideal system to investigate trophic cascade theory by examining predatory fish populations and associated trophic interactions across management zones.

Thus, the overall aim of this paper is to test for an herbivore-mediated trophic cascade extending from apex predators to the coral reef benthos by determining how herbivorous fishes and benthic communities respond to a human-induced predator density gradient across management zones on the GBR. Under this trophic cascade framework, a decline in apex predators in fished areas is expected to cause an increase in mesopredators, followed by a decrease in herbivorous fishes, and finally, an increase in macroalgae and turf algae and a corresponding decline in coral and CCA cover. Alternatively, a decline in targeted mesopredators in fished areas is expected to cause an increase in territorial damselfishes, followed by an increase in turf algae and a decline in coral cover. To test these hypothesized frameworks, we examined whether the observed trophic structure on the GBR fits the ecological predictions of trophic cascade theory.

\section{Materials and methods}

\section{Study sites}

This study was undertaken on 15 spatially separated coral reefs on the outer GBR, Australia, at two distinct latitudes: the Ribbon Reefs at $14^{\circ} \mathrm{S}$ and the Swains Reefs at $21^{\circ} \mathrm{S}$ (Fig. 1). Data were collected between February and April (austral summer months) in 2013 and 2014. We examined three management zones designated by the GBR Marine Park Authority: (1) fished zones that are open to general use and permit fishing and collecting, (2) no-take zones that permit diving and boating activities but prohibit extractive activities (i.e. fishing), and (3) no-entry zones that are strictly enforced preservation zones that are inaccessible for all human activities. In the Ribbon Reefs, we surveyed six reefs, two per management category: Jewell and Hicks Reefs (fished), Day and Yonge Reefs (no-take), and Carter and Hilder Reefs (no-entry). While the majority of trophic surveys on the GBR only include an examination of open fishing and no-take zones (i.e. Russ et al. 2008; Emslie et al. 2015), the inclusion of no-entry zones provides a unique opportunity to compare no-entry zones to open fishing and no-take zones. By taking into account no-entry zones, we utilize a broader, three-tiered predator density gradient to elucidate potential top-down effects on non-targeted fishes and benthic composition across management zones in the GBR. In the Swains, we surveyed nine reefs, three per management category: fished, no-take, and no-entry. Altogether, we surveyed five reefs in each management zone. At the time of the study, the duration of protection of the reefs in no-take and no-entry zones ranged from 11 to 27 years (see Online Resource Table S1).

\section{Study species}

To quantify apex predators, mesopredators, and herbivorous fishes on the GBR, we further split these categories into several groups. Apex predators included all reef shark species, which comprise the top trophic level on coral reefs: T. obesus, C. amblyrhynchos, C. melanopterus, and C. albimarginatus. Mesopredators were categorized as either targeted or non-targeted mesopredators, depending 

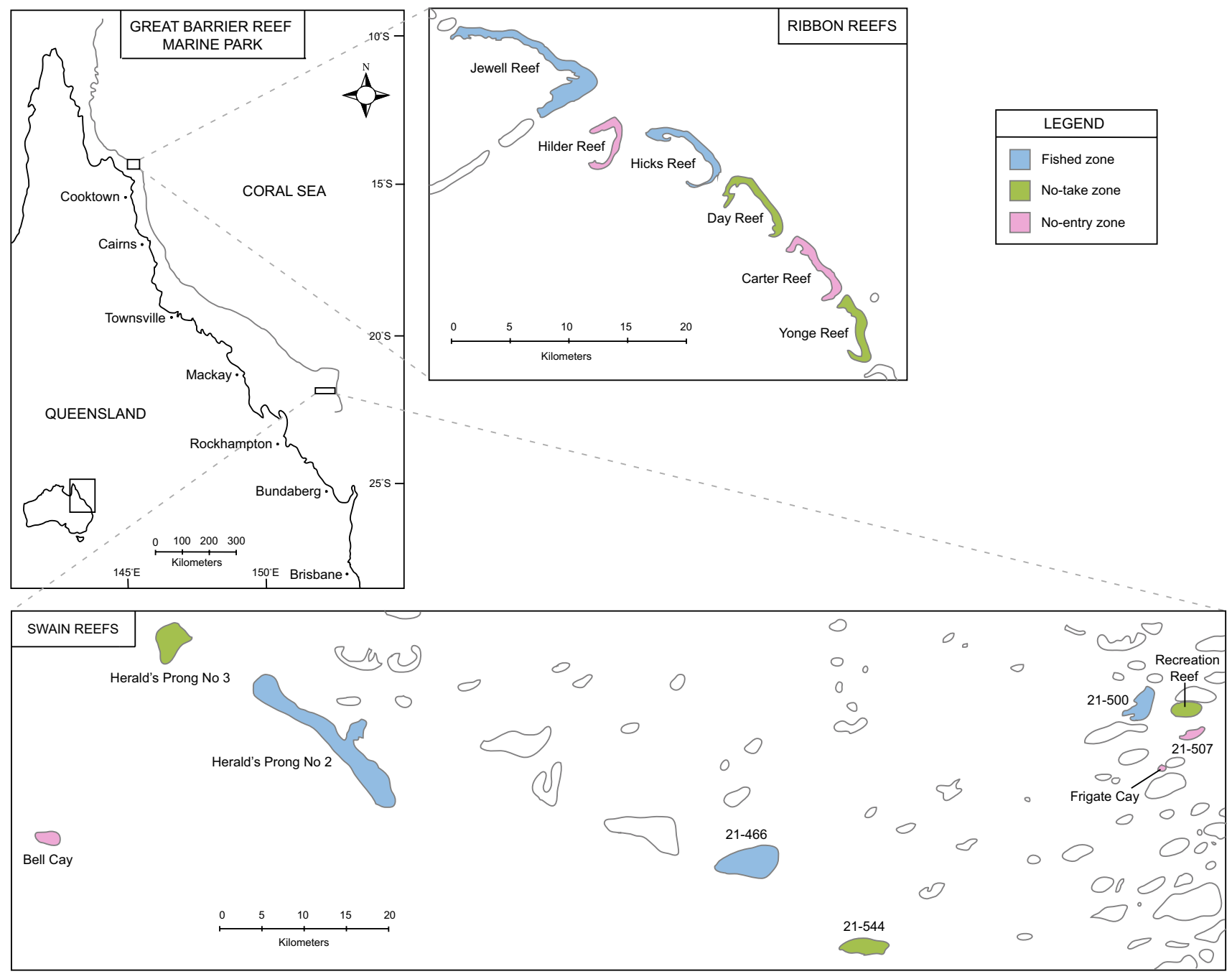

Fig. 1 Map of the study reefs in the Great Barrier Reef Marine Park. Six reefs were surveyed in the Ribbons Reefs (Jewell, Hicks, Day, Yonge, Carter, and Hilder Reefs), and nine reefs were surveyed in the Swain Reefs (Herald's Prong No. 2, Unnamed 21-466, Unnamed 21-500, Herald's Prong No. 3, Unnamed 21-544, Recreation, Bell Cay, Frigate Cay, and Unnamed 21-507 Reefs) on recreational and commercial fisheries (Frisch et al. 2014). Targeted mesopredators included Plectropomus laevis, P. leopardus, Lethrinus miniatus, and Lutjanus carponotatus. Non-targeted predators included all other members of the families Lethrinidae, Lutjanidae, Serranidae, and Haemulidae, and the labrid genera Choerodon and Cheilinus. Herbivorous fishes were split into mobile herbivores and territorial grazers. Mobile herbivores included Labridae in the tribe Scarini (parrotfishes) and the families Acanthuridae, Siganidae, and Kyphosidae. Territorial grazers were composed of territorial members of the family Pomacentridae. To survey for benthic composition, corals were identified to species, macroalgae were identified to genus, and other benthic classifications included turf algae, CCA, soft coral, sponges, rubble, and sand.

\section{Visual censuses}

To assess the density and biomass of reef fishes and benthic composition, we used underwater visual censuses. Each reef was surveyed at four different sites. The study sites were on the reef slope, at a depth of 6-10 m. For the apex predator surveys, an observer conducted two 45-min timed swims at each site and recorded the abundance and estimated total length (TL) of apex predators identified to species (see Rizzari et al. 2015). For the targeted mesopredator, non-targeted mesopredator, mobile herbivore, territorial 


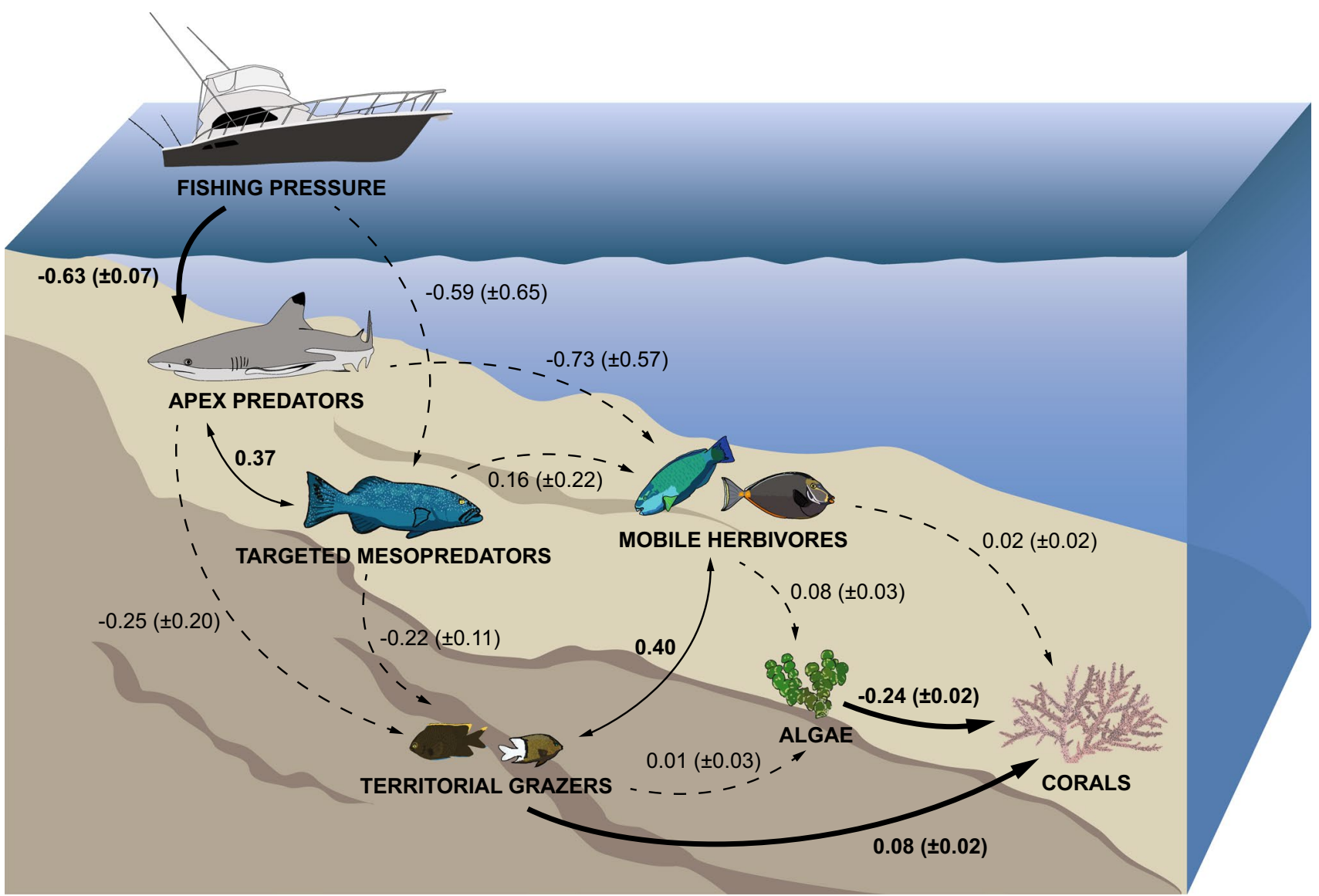

Fig. 2 Directed acyclic graph (DAG), describing theoretical predictions of trophic cascades from apex predators to the benthos on coral reefs. Values are the raw regression coefficients assigned to paths. Thick black arrows and bold values indicate significant pathways $(p<0.01)$ in the direction predicted by a herbivore-mediated trophic cascade; dotted arrows indicate non-significant pathways. Doubleheaded arrows indicate correlated error structure due to shared sources of variability between trophic groups grazer, and benthic composition surveys, three observers laid four $50 \mathrm{~m}$ transects at each site, with each transect at least $10 \mathrm{~m}$ apart. The first observer laid the $50 \mathrm{~m}$ transects and used $10 \mathrm{~m}$-wide belt transects to record the abundance and estimated TL (to the nearest $2 \mathrm{~cm}$ ) of adult (individuals $>10 \mathrm{~cm}$ ) targeted mesopredators, adult non-targeted mesopredators, and adult mobile herbivores identified to species (mesopredators) or family (mobile herbivores). The second observer followed the same $50 \mathrm{~m}$ transects, but used $2 \mathrm{~m}$-wide belt transect to record the abundance of adult territorial grazers identified to species. A third observer used the point intercept method (PIT), recording the benthic composition every $50 \mathrm{~cm}$ along the same $50 \mathrm{~m}$ transects. Consequently, at each reef, there was a total of eight transects (timed swims) for the apex predator surveys and sixteen transects for all other surveys (mesopredator, mobile herbivore, territorial grazer, and benthic composition). To calculate the biomass of fishes, we used published lengthweight relationships (Kulbicki et al. 2005) and converted all values to kilograms per hectare.

\section{Data analysis}

\section{Fit of data to a theoretical trophic cascade}

To determine whether our dataset fits the theoretical predictions of our hypothesized trophic cascade, we fit two piecewise structural equation models (SEMs) to the data. By fitting multiple models to a series of response variables, SEMs have the capacity to rigorously estimate indirect effects and causal links within complex networks (Grace 2006; Duffy et al. 2015). Piecewise SEMs incorporate several linear models into a single causal pathway analysis using directional separation (d-separation) tests (series of independence claims that statistically identify causal relationships and missing links (i.e. pathways) in a directed acyclic graph (DAG); Shipley 2009). Unlike a traditional SEM, piecewise SEMs are capable of including nested models, random effects, non-normal distributions, and are less dependent on large sample sizes (Lefcheck and Duffy 2015). Thus, piecewise SEMs are applicable to nested 
ecological count data such as our dataset. We constructed the piecewise SEMs based on the theoretical framework of a coral reef trophic cascade (Fig. 2). Specifically, we predicted an effect of management zone or protection (fished [unprotected] vs. no-take and no-entry [protected]) on fished predators (apex predators and mesopredators), which we hypothesized to cascade through to herbivorous fishes (mobile herbivores and territorial grazers) and benthic composition (corals and algae). In addition, we specified correlated error structures between apex predators and mesopredators as well as between mobile herbivores and territorial grazers since both combinations of trophic groups are subject to shared sources of variability (arising from fishing pressure/prey availability and predation pressure/prey availability, respectively). Model specifications for the first SEM included six nested mixed-effects models for the density of apex predators, targeted mesopredators, mobile herbivores, territorial grazers, corals, and algae (see Online Resource Table S2). We fit a second SEM, which includes all of the same mixed effects, except for using all mesopredators (targeted and non-targeted mesopredators) instead of only targeted mesopredators since the ecological impact of all mesopredators on lower trophic levels may be less dependent on fishing pressure (see Online Resource Table S3).

To ensure a thorough consideration of alternative hypotheses to the linear trophic cascade models, we fit five additional piecewise SEMs that differed in topology or for which the data were parsed by region. The third piecewise SEM includes targeted mesopredators and non-targeted mesopredators as separate categories since non-targeted mesopredators may undergo a release in predation (from apex predators) as well as a release in competition (from targeted mesopredators), which may lead to non-targeted mesopredators having a distinct impact on lower trophic levels in comparison to targeted mesopredators (see Online Resource Table S4). Further, recent studies suggest that reef sharks, which make up the apex predator category in the current study, may actually occupy a trophic level similar to that of species typically classified as mesopredators (Heupel et al. 2014; Frisch et al. 2016; Roff et al. 2016). Therefore, the fourth piecewise SEM combines apex predators and targeted mesopredators in a single category (all targeted predators; see Online Resource Table S5). The fifth piecewise SEM uses the combined "all targeted predators" category as well as including non-targeted mesopredators as a separate category (see Online Resource Table S6). Lastly, we included two piecewise SEMs that analyse the two regions (the Ribbon Reefs and the Swains Reefs) separately to ensure that the relationships in the model are not primarily driven by regional variability (see Online Resource Tables S7-S8).
To facilitate interpretation and ensure model convergence, we normalized all predictor variables to have a mean of zero and a standard deviation of one prior to running the models. We formulated these models with either the package nlme (Pinheiro et al. 2016) to fit a generalized linear model (GLM) and linear mixed-effects (LME) models or the package lme4 (Bates et al. 2015) to fit generalized mixed-effects models (GLMM). Random effects were specified as site nested within reef. We examined model assumptions, including normality of errors and homogeneity of variances, graphically. To correct for heteroscedasticity and non-normality, square-root transformations were applied to the density of apex predators, targeted/all mesopredators, mobile herbivores, and territorial grazers, and Poisson distributions were used for counts of corals and turf algae. To check the fit of square-root transformations, we assessed residual plots, which were approximately normally distributed and did not reveal deviations from homoscedasticity. When Poisson distributions were applied, model fit was assessed using Pearson Chi-squared tests. The piecewise SEM was performed with the package piecewiseSEM (Lefcheck 2015; Lefcheck and Duffy 2015). The SEM fit was examined using the null probabilities associated with each independence claim $(k)$ from Shipley's d-separation test. To assess whether probabilities were likely to occur by chance, the sum of the null probabilities were tested against a Chi-squared distribution with $2 \mathrm{k}$ degrees of freedom, which yielded Fisher's $C$ statistic, a value that permits the acceptance or rejection of the causal model based on statistical significance. Shipley's d-Regression coefficients for each pathway were extracted from the piecewise SEM. Partial effects plots were generated to assess the direction and magnitude of each pathway with the package effects (Fox 2003). The software program R ( R Development Core Team 2016) was used for all analyses.

\section{Effects of region and management zones on trophic groups}

To assess the effects of region (Ribbons and Swains) and management zone (fished, no-take, and no-entry; using fished as the baseline and thus the intercept parameter in the fitted models) on the densities of different trophic groups (dependent variables), we used the package nlme (Pinheiro et al. 2016) to fit linear mixed-effects (LME) models and the packages MASS (Venables and Ripley 2002) and glmmADMB (Fournier et al. 2012) to fit generalized mixed-effects models (GLMM) (see Online Resource Table S9). As fixed effects, we used region, management zone, and their interaction. As random effects, we used reef, site, or site nested within reef. We examined model assumptions, including normality of errors and homogeneity of variances, graphically. To correct for heteroscedasticity and non-normality, we applied square-root 
transformations, a log transformation, a Poisson distribution, and negative binomial distributions. To check the fit of square-root transformations and the log transformation, we assessed residual plots, which were approximately normally distributed and did not reveal deviations from homoscedasticity. After applying the Poisson and the negative binomial distributions, model fit was assessed using Pearson Chi-squared tests. To obtain global model values for the relative significance of region, management zone, and their interactions for the LME models, we used ANOVAs, which use Chi-squared comparisons of a null model against models including the respective factor. To obtain global model values for the GLMMs, we used the package aod (Lesnoff and Lancelot 2012) to perform Wald tests, which use a Wald Chi-squared test for coefficients given their variance-covariance matrix. The software program $R(R$ Development Core Team 2016) was used for all analyses.

\section{Results}

\section{Fit of data to a theoretical trophic cascade}

From the first piecewise SEM including targeted mesopredators only, the d-separation tests indicated that there were no missing pathways (Online Resource Table S10), resulting in an acceptable global fit of the model to the data $(C=20.77, d f=16, p=0.188)$ (where $p>0.05$ indicates an acceptable model fit; Shipley 2009). This SEM revealed that there were only two significant pathways in

Table 1 Piecewise SEM coefficients from each pathway and correlated error structures based on a theoretical trophic cascade model including targeted mesopredators on coral reefs (see Fig. 2)

\begin{tabular}{lrrr}
\hline Path & Estimate & SE & $p$ value \\
\hline Fishing $\rightarrow$ apex predators & -0.627 & 0.069 & $<0.001$ \\
Fishing $\rightarrow$ targeted mesopredators & -0.590 & 0.650 & 0.381 \\
Apex predators $\rightarrow$ mobile herbivores & -0.733 & 0.570 & 0.221 \\
Targeted predators $\rightarrow$ mobile herbivores & 0.154 & 0.224 & 0.491 \\
Apex predators $\rightarrow$ territorial grazers & -0.260 & 0.213 & 0.244 \\
Targeted predators $\rightarrow$ territorial grazers & -0.194 & 0.111 & 0.092 \\
Mobile herbivores $\rightarrow$ algae & 0.075 & 0.029 & 0.011 \\
Territorial grazers $\rightarrow$ algae & 0.005 & 0.027 & 0.840 \\
Mobile herbivores $\rightarrow$ coral & 0.023 & 0.023 & 0.308 \\
Territorial grazers $\rightarrow$ coral & 0.079 & 0.023 & 0.001 \\
Algae $\rightarrow$ coral & -0.246 & 0.024 & $<0.001$ \\
Correlated error structure & & & \\
Apex predators $\sim$ targeted mesopredators & 0.368 & NA & $<0.001$ \\
Mobile herbivores $\sim ~$ territorial grazers & 0.395 & NA & $<0.001$ \\
\hline
\end{tabular}

Values in italics are statistically significant $(p<0.01)$ the predicted direction: fished zones had a strong negative effect on apex predators $(p<0.001)$ and algae had a negative correlation with live coral, which, given the direct competitive nature of corals and algae on coral reefs, is an expected well-accepted relationship regardless of the predictions of trophic cascade theory $(p<0.001$; Table 1 ; Fig. 2). Correlated error structures between apex predators and targeted mesopredators as well as between mobile herbivores and territorial grazers were significant and positive ( $p<0.001$ for both), suggesting shared sources of variation for both combinations of predatory and herbivorous trophic groups. Two additional pathways show a marginally non-significant (at $\alpha=0.01$ ) positive relationship between mobile herbivores and algae $(p=0.011)$ and a significant positive impact of territorial grazers on live coral ( $p=0.001)$; however, these relationships are opposite to that predicted by the trophic cascade hypothesis tested here. Partial effect plots demonstrate the direction and magnitude of each pathway, including weak, but non-significant, links (Fig. 3). There were no cascading linkages throughout the trophic schematic: mesopredator density was not negatively correlated with mobile herbivore and territorial grazer densities, and herbivorous fish density was not negatively correlated with algae or positively correlated with coral density. From the second SEM, re-fitting the model with all mesopredators (targeted and non-targeted mesopredators combined) did not change the main results of the model $(C=24.38, d f=16, p=0.081)$; however, the correlated error structure between apex predators and all mesopredators was non-significant, indicating that the mechanism that shapes apex predator and targeted mesopredator communities (fishing pressure) does not apply when non-targeted predators are combined with targeted mesopredators (full results in Online Resource Table S11). This provides circumstantial evidence in support of our hypothesis that correlated error structure reflects the effects of variation in fishing pressure among fished reefs since residual variation in apex predator and targeted mesopredator abundances are correlated with each other, but this correlation is not present with residual variation in non-targeted mesopredator abundance.

Re-fitting the model to test alternative hypotheses revealed few alternative explanations to the original trophic cascade model. From the third SEM, incorporating targeted mesopredators and non-targeted mesopredators separately in the model did not change the main results $(C=34.48$, $d f=24, p=0.077$ ), nor did the model indicate that nontargeted mesopredators have a distinct impact on lower trophic levels when considered separately from targeted mesopredators (full results in Online Resource Table S12). From the fourth SEM, combining all apex predators and targeted mesopredators into a single targeted predator 

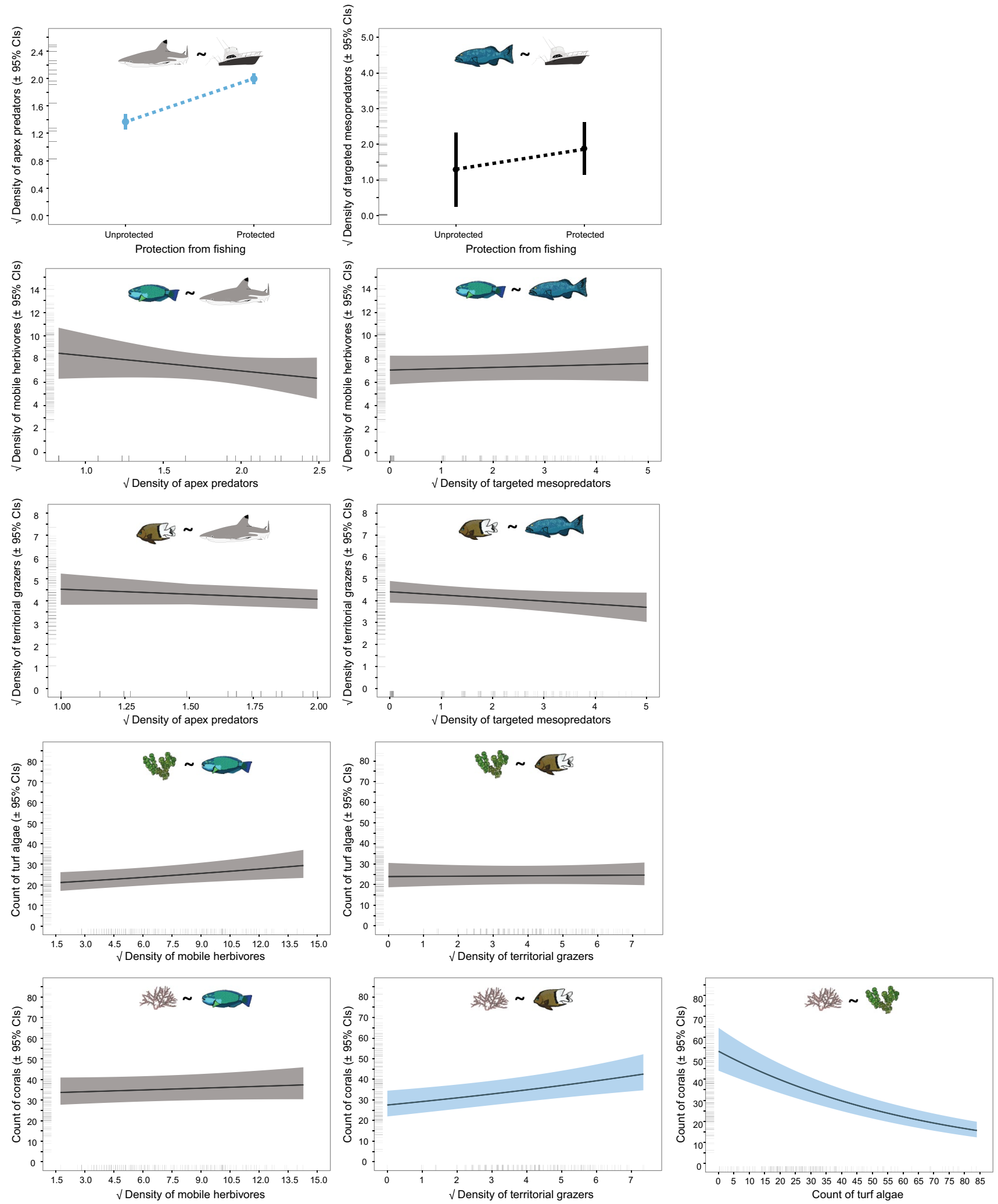

Fig. 3 Partial effect plots for each pathway in the piecewise SEM (see Table 1; Fig. 2). Trend lines represent the mean fit for each pathway with all other predictor variables held constant. Whiskers (for plots in top row) and shaded areas (for plots in all other rows) represent the $\pm 95 \%$ confidence intervals (CIs). Rugs on the $x$ - and $y$-axes indicate the occurrences of raw values, and a random jitter was applied to disentangle overlapping raw values. The $y$-axis of each plot was fixed at zero to facilitate the comparison of effects. Models with a Poisson error distribution and log-link function (plots in the two bottom rows) were plotted on the scale of the response. Light blue indicates significant pathways $(p<0.01)$ (color figure online) 
category provided no evidence that considering apex predators as high-level mesopredators changes the lack of evidence for trophic cascades in our system $(C=12.32$, $d f=12, p=0.421$; full results in Online Resource Table S13). Likewise, using the singular all targeted predators category in conjunction with non-targeted predators did not reveal any evidence of trophic cascades $(C=18.19$, $d f=16, p=0.313$; full results in Online Resource Table S14). Lastly, considering the original piecewise SEM for each region separately did not reveal any changes in the main results for the Ribbons Reefs $(C=76.23, d f=16$, $p=0.582$; full results in Online Resource Table S15) or the Swains Reefs $(C=14.22, d f=16, p=0.582$; full results in Online Resource Table S16), indicating that the biotic differences between the two regions did not obscure the detectability of potential cascading effects.

\section{Effects of region and management zones on trophic groups}

Models predicting spatial variation in fish density revealed that some groups of fishes increased in density in no-take and no-entry zones, but this was highly dependent on region (Fig. 4a; Online Resource Table S17; Online Resource Table S18; Online Resource Table S19). As compared to fished zones, apex predator density was significantly higher in no-entry zones in both the Ribbons and the Swains. In the Ribbon Reefs, the density of apex predators was approximately fourfold (4.27 $\pm 1.62 ; 95 \%$ confidence interval (CI) based on raw values) higher in no-entry zones as compared to fished zones, and in the Swain Reefs, the density of apex predators was approximately twofold $(1.73 \pm 0.60 ; 95 \%$ CI based on raw values) higher in no-entry zones as compared to fished zones. However, targeted and non-targeted mesopredator density was higher in no-take zones only in the Swains, and mobile herbivore density was higher in only no-entry zones in the Swains. The density of territorial grazers exhibited an interaction between region and management zone; they were lower in no-entry zones in the Ribbons (although this effect was non-significant) and higher in no-entry zones in the Swains (Online Resource Table S17). With the exception of fished and no-entry zones for apex predators, region had a significant impact on the density of fishes across management zones (Online Resource Table S18). For fish density, strong regional effects include (on average across reefs, comparing Ribbons to Swains): an approximately 14-fold (14.74 $\pm 3.50 ; 95 \%$ CI based on raw values) higher density of targeted mesopredators in the Swains, twofold ( $2.42 \pm 0.43 ; 95 \%$ CI based on raw values) higher density of non-targeted mesopredators in the Ribbons, threefold (2.79 $\pm 0.28 ; 95 \% \mathrm{CI}$ based on raw values) higher density of mobile herbivores in the Ribbons, and twofold $(1.91 \pm 0.17 ; 95 \%$ CI based on raw values) higher density

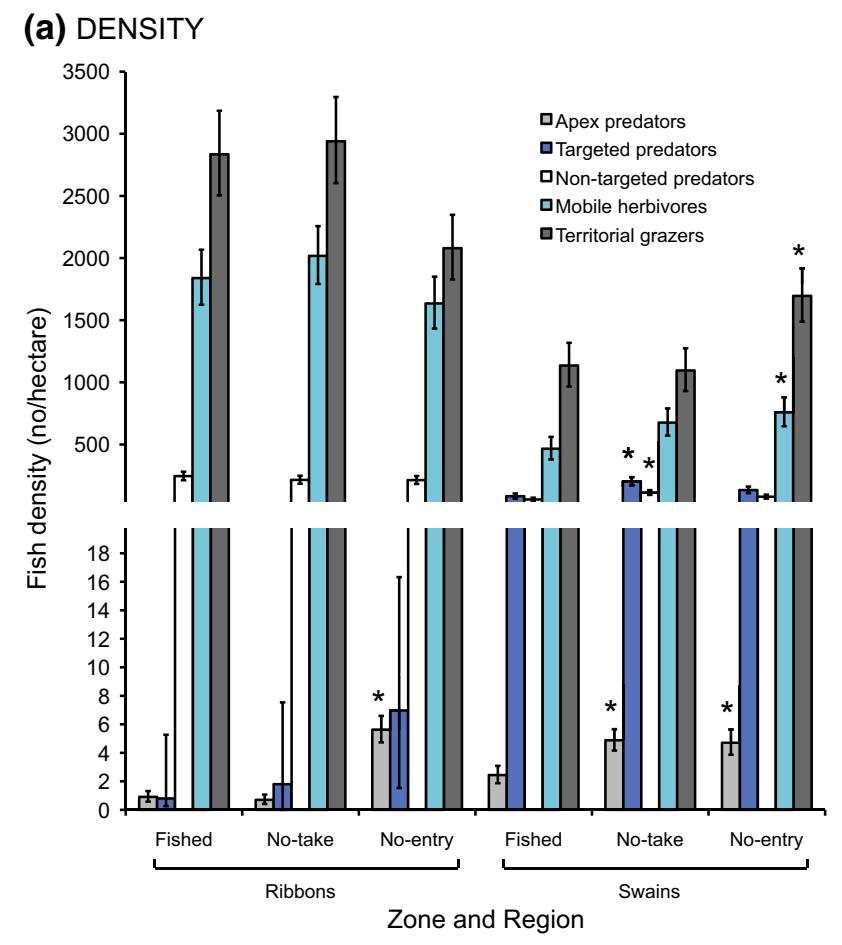

(b) BIOMASS

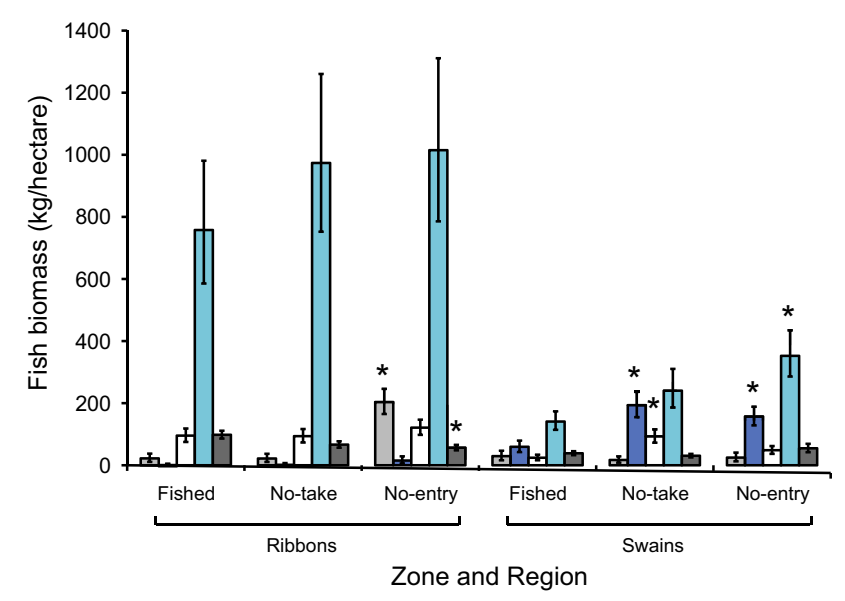

Fig. 4 Back-transformed values ( \pm SE) from LME models of fish (a) density (number/ha) and (b) biomass (kg/ha) for the two geographic regions (Ribbon Reefs and Swain Reefs) across fished, no-take, and no-entry management zones (per management zone: $n=16$ for apex predators in the Ribbons, $n=32$ for apex predators in the Swains, $n=32$ for all other trophic groups in the Ribbons, $n=48$ for all other trophic groups in the Swains). Asterisks indicate significant values $(p<0.05)$, which represent tests of the null hypothesis that the relevant treatment differs from fished zones from each respective region

of territorial grazers in the Ribbons (Online Resource Table S17). Likewise, global model values show that region has a significant effect on the density of all fish trophic groups; however, only apex predators were significantly impacted by management zone (Online Resource Table S19). 
Similarly, fish biomass increased for some groups of fishes in no-take and no-entry zones, but this was also highly dependent on region (Fig. 4b; Online Resource Table S18; Online Resource Table S19; Online Resource Table S20). In the Ribbons, the biomass of apex predators was approximately fivefold $(4.52 \pm 2.39 ; 95 \%$ CI based on raw values) higher in no-entry zones as compared to fished zones, but in the Swains, there was no significant difference in the biomass of apex predators. Targeted mesopredator biomass was higher only in no-take zones in the Swains. Non-targeted mesopredator biomass was higher in no-take and no-entry zones in the Swains. Mobile herbivores were only higher in no-entry zones in the Swains. Territorial grazer biomass was lower in no-entry zones in the Ribbons (Online Resource Table S20). Again, region had a significant effect across management zones for fish biomass, with the exception of fished and no-take zones for apex predators, no-take zones for non-targeted mesopredators, and noentry zones for territorial grazers (Online Resource Table S18). For apex predators in no-entry zones, there was an approximately twofold $(2.33 \pm 0.89 ; 95 \%$ CI based on raw values) higher biomass in the Ribbons compared to the Swains. As reported for fish density, similar strong regional effects prevailed for fish biomass (on average across reefs, comparing Ribbons to Swains): there was an approximately eightfold $(8.11 \pm 2.98 ; 95 \%$ CI based on raw values) higher biomass of targeted mesopredators in the Swains, twofold $(1.82 \pm 0.49 ; 95 \%$ CI based on raw values) higher biomass of non-targeted mesopredators in the Ribbons, threefold $(3.21 \pm 0.62 ; 95 \%$ CI based on raw values) higher biomass of mobile herbivores in the Ribbons, and twofold (1.74 $\pm 0.12 ; 95 \% \mathrm{CI}$ based on raw values) higher biomass of territorial grazers in the Ribbons (Online Resource Table S20). Likewise, global model values show that region has a significant effect on the biomass of all fish trophic groups, and apex predators, targeted mesopredators, and herbivores were significantly impacted by management zone (Online Resource Table S19).

Unlike the fish results, the benthic models revealed that management zones had no significant impact on benthic composition, and region had a limited effect on overall benthic composition (Fig. 5; Online Resource Table S18; Online Resource Table S19; Online Resource Table S21). There was a significant effect of region on no-take and noentry zones for CCA as well as for rubble and sand, with CCA having an approximately eightfold $(7.63 \pm 2.82$; $95 \%$ CI based on raw values) higher density in the Ribbons compared to the Swains, while rubble and sand had an approximately fourfold (3.84 $\pm 0.79 ; 95 \% \mathrm{CI}$ based on raw values) higher abundance in the Swains compared to the Ribbons (Online Resource Table S18; Online Resource Table S21). Similarly, global model values show that region has a significant effect on CCA as well as rubble and sand;

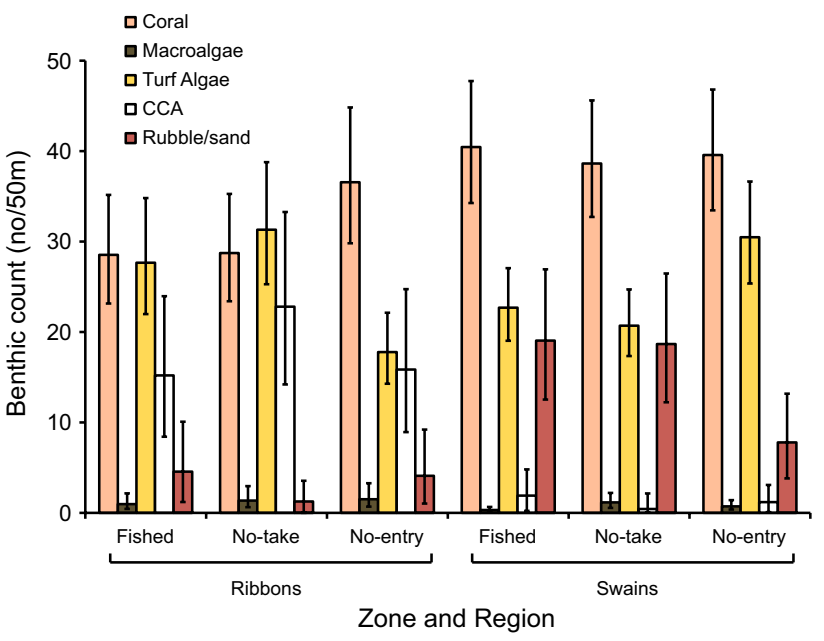

Fig. 5 Back-transformed values $( \pm \mathrm{SE})$ from LME models and GLMMs of benthic composition (number $/ 50 \mathrm{~m}$ ) for the two geographic regions (Ribbon Reefs and Swain Reefs) across fished, notake, and no-entry management zones (per management zone: $n=32$ in the Ribbons, $n=48$ in the Swains). Asterisks indicate significant values $(p<0.05)$, which represent tests of the null hypothesis that the relevant treatment differs from fished zones from each respective region

however, there were no significant effects of zone on any of the benthic groups (Online Resource Table S19).

\section{Discussion}

Despite a fourfold $(4.27 \pm 1.62 ; 95 \%$ CI based on raw values) gradient in the density of apex predators (from a low of 1.4 sharks per hectare in fished zones in the Ribbons to a high of 5.98 sharks per hectare in no-entry zones in the Ribbons) and a 38-fold (38.22 $\pm 22.14 ; 95 \%$ CI based on raw values) gradient in the density of targeted mesopredators (from a low of 5.63 targeted mesopredators per hectare in fished zones in the Ribbons to a high of 215 targeted mesopredators per hectare in no-take zones in the Swains), there was no evidence for cascading effects to lower trophic levels, including mobile herbivores, territorial grazers, and benthic composition in the world's largest coral reef system. The density and biomass of mesopredators and herbivorous fishes were highly dependent on region, and less so on management zone, with only the density of apex predators and targeted mesopredators increasing in protected areas in both regions. However, we found no evidence of mesopredator release or prey release, and there was no correlation between the densities of predators and herbivorous fishes. Further, fish assemblages and management zones had little effect on benthic composition, although there were some differences in benthic assemblages between the northern and southern regions. Our results are 
largely consistent with recently published distributions of apex predators, targeted mesopredators, and herbivorous fishes on the GBR (Rizzari et al. 2015). Similarly, despite increased biomass and densities of targeted mesopredators in no-take zones as compared to fished zones, non-targeted members of the fish assemblage and hard coral cover did not reveal clear patterns across management zones (Emslie et al. 2015). The regional variations in fish and benthic assemblages and the inconsistency of our results with trophic cascade theory via a herbivore-pathway highlight the importance of considering environmental factors associated with geographic region and oceanic productivity in marine trophic interactions alongside human impacts such as fishing (Salomon et al. 2010; Taylor 2014; Jouffray et al. 2015; Williams et al. 2015a, b).

Our application of a structural equation model directly tests trophic cascade theory, demonstrating that apex predators and targeted mesopredators have minimal top-down effects across management zones on the outer GBR. These findings contrast with previous examples of putative humaninduced trophic cascades on coral reefs. Whereas we found that the removal of predators by fishing had no cascading effects on fish or benthic assemblages, previous work has suggested that the loss of predators is associated with cascading effects to lower trophic levels (Sandin et al. 2008; Ruppert et al. 2013). Consistent with our results, fishinginduced declines in apex predators and mesopredators in the Line Islands did not affect the overall density of herbivorous fishes (Sandin et al. 2008). Conversely, while Sandin et al. (2008) attributed a reduction in predation to a 60 -fold increase in the biomass of territorial damselfishes as well as an increase in planktivorous fish density and macroalgae and turf algae cover, we found no relationship between predator density and territorial damselfishes and a positive relationship between territorial damselfishes and coral cover on the outer GBR. The coexistence of territorial damselfishes with high coral cover may be attributed to the comparatively light farming behaviours of territorial damselfishes on the reef slope and the high territorial turnover rates of damselfishes on exposed reefs, which may alleviate the negative effects of algal farming behaviours and permit recovery phases for corals (Casey et al. 2015). Unlike the GBR, predator fishing in the Line Islands co-varies with other human impacts such as the extraction of herbivorous fishes, pollution, and runoff, which may account for the discrepancy between these studies. In another recent study in northwestern Australia, Ruppert et al. (2013) suggested that a threefold higher density of apex predators on non-fished versus fished reefs resulted in a lower density of mesopredators and a higher density of herbivorous fishes due to mesopredator release, which differs from our results. This difference could be due to extensive fishing pressure across many trophic levels [including the extraction of predators, herbivorous fishes, sea cucumbers (Holothuroidea spp.), and top snails (Trochidae spp.)] from northwestern Australia, which likely confounds the effects of predator removal from this system. In that study, region is also confounded with fishing pressure since the protected reefs are all in one reef system, and fished reefs are all located in a different system that is spatially separated by three degrees latitude. That design contrasts with the GBR, which makes possible a study design that includes spatially interspersed, replicate protected and fished reefs within the different regions.

Global trends of herbivorous fish densities also reveal a contrasting pattern to our results: in a global meta-analysis of fishing effects on herbivorous fishes, significant reductions in the biomass of mobile herbivores were reported in fished areas, while territorial grazers increased in density and biomass under fishing pressure (Edwards et al. 2014). Again, in the majority of regions included in this meta-analysis, such as the Caribbean and the South Pacific Islands, extensive fishing for herbivorous fishes and pollution likely co-vary with effects of predator removal on coral reefs. In contrast, our analysis of how marine protected areas affect fish and benthic communities excludes confounding factors such as the extraction of other trophic levels, pollution, and runoff, permitting a more targeted assessment of trophic cascade theory on coral reefs. Our findings demonstrate the importance of distinguishing between fishing-induced trophic cascades that are solely instigated by the loss of predators rather than broader anthropogenic-induced ecosystem collapse on coral reefs, which is often due to a multitude of factors in addition to fishing pressure. However, given the high variability of environmental and biological factors such as productivity, habitat complexity, and species richness on coral reefs, the detectability of trophic cascades may significantly differ among geographically distinct reef systems (Salomon et al. 2010; Edwards et al. 2010; Williams et al. 2015a).

This study reveals substantial differences in fish assemblages between the two regions, with a higher density and biomass of targeted mesopredators in the Swains and a higher density and biomass of non-targeted mesopredators, mobile herbivores, and territorial grazers in the Ribbons. Regional effects may exist due to differences in environmental conditions such as nutrient input and reef geomorphology across the GBR (Hutchings et al. 2008) or biophysical factors (i.e. sea surface temperature, wave energy, system productivity; Williams et al. 2015a). In a post hoc evaluation of nutrient availability on the reefs included in this study (Online Resource Table S22), we found no difference in nutrient availability among the management zones (ANOVA: $F(2,12)=0.64, p=0.544)$ or between the regions (paired two-tailed $t$ test: $t=-1.207, d f=12.971$, $p=0.249$ ). Another regional factor may be the heterogeneous effects of stochastic disturbance events such 
as cyclones and bleaching events (Jouffray et al. 2015). According to a long-term monitoring program across the GBR, there have been no changes in coral cover attributed to specific disturbance events between 1986 and 2004 in the Ribbon Reefs; conversely, in the outer Swain Reefs, recurrent crown-of-thorns starfish (Acanthaster planci) outbreaks in 1991 and 2001-2004 have caused severe declines in branching coral cover, especially Acropora spp. (Sweatman et al. 2011). Declines in acroporid cover, and thus habitat complexity, are associated with the loss of small-bodied coral-associated fishes, such as territorial damselfishes (Emslie et al. 2008; Brandl et al. 2016), which may explain the lower density and biomass of territorial grazers in the Swains compared to the Ribbons. Bottom-up effects that shape habitat complexity and populations of small-bodied fishes likewise drive prey availability to large piscivores (Alvarez-Filip et al. 2011a), and in Fiji, the loss of habitat complexity and thus prey availability is a more important driver of piscivore assemblages than fishing pressure (Wilson et al. 2008). Further, the architectural complexity offered by acroporid cover may drive additional ecosystem services such as wave energy and nutrient upcycling, thus further impacting the trophic structure of fish assemblages (Alvarez-Filip et al. 2011b). In the current study, we did not consider the direct or indirect bottom-up effects of habitat complexity on trophic dynamics, which may partially explain some of the biotic patterns that we found.

Further, although all of the reefs in the present study were on the outer GBR, each reef has a unique set of biophysical and geophysical conditions. For example, nutrient enrichment from seabird colonies or high levels of habitat complexity may have substantial bottom-up effects on coral reef fish populations (Beukers and Jones 1998). Seabird colonies may be an important contributing factor in the Swains because the designation of no-entry zones (e.g. Frigate Cay Reef, one of our study reefs) was based, at least in part, on important seabird and green and loggerhead sea turtle nesting areas rather than other marine conservation priorities (Heatwole et al. 1996). In this context, these nutrientenriched reefs in the Swains are not necessarily strategic conservation areas for fishes or corals, which may offer a partial explanation as to why, for instance, no-entry zones in the Ribbons had a significantly higher biomass of apex predators compared to no-entry zones in the Swains. Given the higher magnitude of regional effects in comparison to fishing effects on the GBR, this demonstrates the need to consider the effects of stochastic disturbances and regional differences in biophysical and geophysical conditions (e.g. Taylor 2014; Williams et al. 2015a) in highly dynamic ecosystems such as coral reefs before attributing differences in fish density and biomass to fishing effects alone. Similar to predator-herbivore interactions, we found no significant cascading trophic links between the density of herbivorous fishes and benthic composition (also see Carassou et al. 2013). However, we found some regional differences in benthic composition, with CCA on average five times as abundant in the Ribbons, and rubble and sand on average nearly five times as abundant in the Swains. This regional difference could be due to a variety of environmental and biogeo-physical conditions that were not directly considered (e.g. the positioning of the reefs on the shelf), which indicates that environmental factors play a larger role in shaping benthic trophic structure than the direct effects of fishing.

Aside from environmental factors, aspects intrinsic to coral reef fish communities may mitigate the effects of apex predator declines on lower trophic levels. Omnivory and trophic versatility are common among species that live on coral reefs, and this violates the rationale that underpins linear trophic cascade theory (Thompson et al. 2007). Omnivory is highly prevalent in tropical fish assemblages (Choat et al. 2004), and it may dampen the effects of consumer influence and prevent the progression of linear trophic cascades (Strong 1992). In a large synthesis assessing the relative strength of trophic cascades across study systems, Borer et al. (2005) highlight the importance of taxonomic distinctness and physiological characteristics in driving trophic cascades. For example, in marine benthic systems, endothermic predators and invertebrate herbivores are most likely to trigger strong trophic cascades. In contrast, on coral reefs, a trophic cascade among different trophic levels of fishes with similar life history traits (i.e. ectothermic vertebrates) is less likely to occur, particularly if the high prevalence of omnivory homogenizes the assemblage. This is further enhanced by trophic versatility, which allows a species to opportunistically feed across several trophic levels, resulting in diffuse predation effects that obscure any prey release when predators are removed (Bellwood et al. 2006). For example, P. leopardus is a frequently targeted mesopredator that is nearly absent from unprotected reefs in the Ribbons but abundant on protected reefs in the Swains. This species has a diverse diet, preying on up to forty different taxa, including pelagic and reef fishes, mollusks, and crustaceans (Kingsford 1992). In contrast, large predatory labrids such as Cheilinus undulatus are protected from fishing and thus equally common on protected and unprotected reefs across the GBR. Similar to P. leopardus, however, they have been reported to consume a wide range of piscine and invertebrate prey (Randall et al. 1978). This dilution of interaction strength in predator-prey relationships in both targeted and non-targeted mesopredators likely explains why we were unable to detect a cascading effect across a gradient of targeted predators. In addition, coral reef food webs are open to pelagic environments due to their spatial discontinuity and extensive exchange with pelagic systems. Spatial heterogeneity of coral reefs enhances nutrient and prey subsidies, which may augment 
predator populations and further intensify the complexity of trophic interactions (Polis et al. 1997). Thus, trophic versatility, omnivory, and open food webs are all factors that considerably obfuscate linear processes such as trophic cascades, and this may explain their rarity on coral reefs.

In contrast to mesopredators and herbivores on coral reefs, which consist almost exclusively of perciform, teleost fishes, the apex predators in the current study, reef sharks, are both taxonomically and physiologically distinct. Given their biological distinctness and presumptive position at the top of the food chain, it would be reasonable to expect strong repercussions from decreases in shark biomass (Borer et al. 2005). However, there are two reasons related to the trophic ecology of reef sharks that may prevent strong cascading effects in wake of their declines. First, while reef sharks are notoriously omnivorous (Frisch et al. 2016), their diets are highly dependent on body size (Wetherbee et al. 1997). Reef sharks undergo ontogenetic shifts in diet as they reach maturity, which means that juvenile reef sharks may be functionally distinct due to limitations in gape size (Scharf et al. 2000). Thus, reef shark size structure is highly relevant on coral reefs due to these ontogenetic shifts, and the inclusion of juvenile and adult reef sharks in the same trophic category may disrupt the presumed effects of a predator-driven trophic cascade. Second, based on dietary analyses and size classes, recent studies suggest that reef sharks may be more appropriately categorized as high-level mesopredators rather than apex predators (Heupel et al. 2014; Frisch et al. 2016; Roff et al. 2016). This reclassification would further elucidate why an "apex predator"-induced trophic cascade was not detected in the present study.

We provide empirical evidence that a herbivore-centric trophic cascade is not detectable on the outer GBR, at least in the Ribbon and Swains Reefs, despite substantially lower densities of predators in fished management zones (Robbins et al. 2006; Emslie et al. 2015). There was no evident cascading impact of predatory fishes on herbivorous fishes or of herbivorous fishes on benthic composition. Our results highlight the need to consider regional effects, biophysical factors, and stochastic disturbances (i.e. A. planci outbreaks in the Swains) in complex marine systems such as coral reefs since indirect effects may play a substantial role in shaping coral reef ecosystems. Our findings also call for a reassessment of trophic interactions on coral reefs given the limited top-down impact of apex predators on fish and benthic communities, which would allow us to better gauge the impact of human-mediated disturbances in the marine environment. Trophic interactions on coral reefs are inherently opportunistic, with high degrees of omnivory and trophic versatility, which may undermine linear processes such as trophic cascades. Understanding complex trophic interactions in an ecosystem is essential to pinpoint weaknesses that may underlie ecological theory, such as the predictions embedded in trophic cascade models.

Acknowledgments We thank O. Lönnstedt, Lizard Island Research Station, and the crew of the Research Vessel James Kirby for field support. We also thank J. Alvarez Romero, D. E. Burkepile, J. H. Choat, J. S. Lefcheck, S. A. Sandin, one anonymous reviewer, and the Ecological Modelling Research Group at James Cook University for helpful comments and discussions that improved the manuscript. Funds were provided by the ARC Centre of Excellence for Coral Reef Studies and James Cook University. All work was carried out under the Great Barrier Reef Marine Parks Authority Permit No. G13/36059.1.

Author contribution statement JMC, AHB, MOH, JRR, AJF, and SRC designed the study. JMC, AHB, SJB, MOH, JRR, AJF, and CEM collected the data. JMC and SJB performed modelling. JMC wrote the first draft of the manuscript, and all authors contributed substantially to revisions.

\section{References}

Alongi DM, McKinnon AD (2005) The cycling and fate of terrestrially-derived sediments and nutrients in the coastal zone of the Great Barrier Reef shelf. Mar Poll Bull 51:239-252

Alvarez-Filip L, Côté IM, Gill JA, Watkinson AR, Dulvy NK (2011b) Region-wide temporal and spatial variation in Caribbean reef architecture: is coral cover the whole story? Glob Change Biol 17:2470-2477

Alvarez-Filip L, Gill JA, Dulvy NK (2011a) Complex reef architecture supports more small-bodied fishes and longer food chains on Caribbean reefs. Ecosphere 2:118

Bates D, Maechler M, Bolker BM, Walker S (2015) Fitting linear mixed-effects models using lme4. J Stat Softw 67:1-48

Baum JK, Worm BM (2009) Cascading top-down effects of changing oceanic predator abundances. J Anim Ecol 78:699-714

Bellwood DR, Wainwright PC, Fulton CJ, Hoey AS (2006) Functional versatility supports coral reef biodiversity. Proc R Soc B 273:101-107

Beukers JS, Jones GP (1998) Habitat complexity modifies the impact of piscivores on a coral reef fish population. Oecologia 114:50-59

Borer ET, Seabloom EW, Shurin JB, Anderson KE, Blanchette CA, Broitman B, Cooper SD, Halpern BS (2005) What determines the strength of a trophic cascade? Ecology 86:528-537

Brandl SJ, Emslie MJ, Ceccarelli DM (2016) Habitat degradation increases functional originality in highly diverse coral reef fish assemblages. Ecosphere (in press)

Byrnes J, Stachowicz JJ, Hultgren KM, Hughes AR, Olyarnik SV, Thornbert CS (2006) Predator diversity strengthens trophic cascades in kelp forests by modifying herbivore behaviour. Ecol Lett 9:61-71

Carassou L, Léopold M, Guillemot N, Wantiez L, Kulbicki M (2013) Does herbivorous fish protection really improve coral reef resilience? A case study from New Caledonia (South Pacific). PLoS One 8:e60564

Casey JM, Ainsworth TD, Choat JH, Connolly SR (2014) Farming behaviour of reef fishes increases the prevalence of coral disease associated microbes and black band disease. Proc R Soc B 281:20141032

Casey JM, Choat JH, Connolly SR (2015) Coupled dynamics of territorial damselfishes and juvenile corals on the reef crest. Coral Reefs 34:1-11 
Cebrian J, Shurin JB, Borer ET, Cardinale BJ, Ngai JT, Smith MD, Fagan WF (2009) Producer nutritional quality controls ecosystem trophic structure. PloS One 4:e4929

Ceccarelli DM, Hughes TP, McCook LJ (2006) Impacts of simulated overfishing on the territoriality of coral reef damselfish. Mar Ecol Prog Ser 309:255-256

Choat JH, Robbins WD, Clements KD (2004) The trophic status of herbivorous fishes on coral reefs. II. Food processing modes and trophodynamics. Mar Biol 145:445-454

Duffy JE, Reynolds PL, Bostrom C, Coyer JA, Cusson M, Donadi S, Douglass JG, Eklof JS, Engelen AH, Eriksson BK, Fredriksen S, Gamfeldt L, Gustafsson C, Hoarau G, Hori M, Hovel K, Iken K, Lefcheck JS, Moksnes P-O, Nakaoka M, O'Connor MI, Olsen JL, Richardson JP, Ruesnik JL, Sotka EE, Thromar J, Whalen MA, Stachowicz JJ (2015) Biodiversity mediates top-down control in eelgrass ecosystems: a global comparative-experimental approach. Ecol Lett 18:696-705

Dulvy NK, Freckleton RP, Polunin NVC (2004) Coral reef cascades and the indirect effects of predator removal by exploitation. Ecol Lett 7:410-416

Edwards KF, Aquilino KM, Best RJ, Sellheim KL, Stachowicz JJ (2010) Prey diversity is associated with weaker consumer effects in a meta-analysis of benthic marine experiments. Ecol Lett 13:194-201

Edwards CB, Friedlander AM, Green AG, Hardt MJ, Sala E, Sweatman HP, Williams ID, Zglicynski B, Sandin S, Smith JE (2014) Global assessment of the status of coral reef herbivorous fishes: evidence for fishing effects. Proc R Soc B 281:20131835

Emslie MJ, Cheal AJ, Sweatman H, DeLean S (2008) Recovery from disturbance of coral and reef fish communities on the Great Barrier Reef, Australia. Mar Ecol Prog Ser 371:177-190

Emslie MJ, Logan M, Williamson DH, Ayling AM, MacNeil MA, Ceccarelli D, Cheal AJ, Evans RD, Johns KA, Jonker MJ, Miller IR, Osborne K, Russ GR, Sweatman HPA (2015) Expectations and outcomes of reserve network performance following re-zoning of the Great Barrier Reef Marine Park. Curr Biol 25:1-10

Eriksson BK, Ljunggren L, Sandström A, Johansson G, Mattila J, Rubach A, Raberg S, Snickars M (2009) Declines in predatory fish promote bloom-forming macroalgae. Ecol Appl 19:1975-1988

Estes JA, Tinker MT, Williams TM, Doak DF (1998) Killer whale predation on sea otters linking oceanic and nearshore ecosystems. Science 282:473-476

Ferretti F, Worm B, Britten GL, Heithaus MR, Lotze HK (2010) Patterns and ecosystem consequences of shark declines in the ocean. Ecol Lett 13:1055-1071

Fournier DA, Skaug HJ, Ancheta J, Ianelli J, Magnusson A, Maunder M, Nielsen A, Sibert J (2012) AD Model Builder: using automatic differentiation for statistical inference of highly parameterized complex nonlinear models. Optim Methods Softw 27:233-249

Fox J (2003) Effect displays in R for generalized linear models. J Stat Soft 8:1-27

Friedlander AM, DeMartini EE (2002) Contrasts in density, size, and biomass of reef fishes between the northwestern and the main Hawaiian Islands: the effects of fishing down apex predators. Mar Ecol Prog Ser 230:253-264

Frisch AJ, Baker R, Hobbs J-PA, Nankervis L (2008) A quantitative comparison of recreational spearfishing and linefishing on the Great Barrier Reef: implications for management of multi-sector coral reef fisheries. Coral Reefs 27:85-95

Frisch AJ, Ireland M, Baker R (2014) Trophic ecology of large predatory reef fishes: energy pathways, trophic level, and implications for fisheries in a changing climate. Mar Biol 161:61-73

Frisch AJ, Ireland M, Rizzari JR, Lonnstedt OM, Magnenat KA, Mirbach CE, Hobbs J-PA (2016) Reassessing the trophic role of reef sharks as apex predators on coral reefs. Coral Reefs 35:459-472
Grace JB (2006) Structural equation modeling and natural systems. Cambridge University Press, Cambridge

Graham NAJ, Evans RD, Russ GR (2003) The effects of marine reserve protection on the trophic relationships of reef fishes on the Great Barrier Reef. Environ Conserv 30:200-208

Harriott VJ (2001) The sustainability of Queensland's coral harvest fishery. Technical Report No. 40. CRC Reef Research Centre, Townsville

Heatwole H, O’Neill P, Jones M, Preker M (1996) Long-term population trends of seabirds on the Swain Reefs, Great Barrier Reefs. Technical Report No. 12. CRC Reef Research Centre, Townsville

Heupel MR, Knip DM, Simpfendorfer CA, Dulvy NK (2014) Sizing up the ecological role of sharks as predators. Mar Ecol Prog Ser 495:291-298

Hutchings PA, Kingsford MJ, Hoegh-Guldberg O (2008) The Great Barrier Reef: biology, environment and management. CSIRO, Townsville

Jackson JBC, Kirby MX, Berger WH, Bjorndal KA, Botsford LW, Bourque BJ, Bradbury RH, Cooke R, Erlandson J, Estes JA, Hughes TP, Kidwell S, Lange CB, Lenihan HS, Pandolfi JM, Peterson CH, Steneck RS, Tegner MJ, Warner RR (2001) Historical overfishing and the recent collapse of coastal ecosystems. Science 293:629-638

Jouffray J-B, Nyström AV, Williams ID, Wedding LM, Kittinger JN, Williams GJ (2015) Identifying multiple coral reef regimes and their drivers across the Hawaiian archipelago. Phil Trans R Soc B 370:20130268

Kingsford MJ (1992) Spatial and temporal variation in predation on reef fishes by coral trout (Plectropomus leopardus, Serranidae). Coral Reefs 11:193-198

Kulbicki M, Guillemot N, Amand M (2005) A general approach to length-weight relationships for New Caledonian lagoon fishes. Cybium 29:235-252

Lefcheck JS (2015) PiecewiseSEM: piecewise structural equation modeling in R for ecology, evolution, and systematics. Methods Ecol Evol 7:573-579

Lefcheck JS, Duffy JE (2015) Multitrophic functional diversity predicts ecosystem functioning in experimental assemblages of estuarine consumers. Ecology 96:2973-2983

Lesnoff M, Lancelot R (2012) Aod: analysis of overdispersed data. R package version 1.3. http://cran.r-project.org/package $=$ aod

Madin EMP, Gaines SD, Madin JS, Warner RR (2010) Fishing indirectly structures macroalgal assemblages by altering herbivore behavior. Am Nat 176:785-801

McCook LJ, Ayling T, Cappo M, Choat JH, Evans RD, De Freitas DM, Heupel M, Hughes TP, Jones GP, Mapstone B, Marsh H, Mills M, Molloy FJ, Pitcher CR, Pressey RL, Russ GR, Sutton S, Sweatman H, Tobin R, Wachenfeld DR, Williamson DH (2010) Adaptive management of the Great Barrier Reef: a globally significant demonstration of the benefits of networks of marine reserves. Proc Natl Acad Sci USA 107:18278-18285

O'Leary JK, McClanahan TR (2010) Trophic cascades result in largescale coralline algae loss through differential grazer effects. Ecology 91:3584-3597

Pace ML, Cole JJ, Carpenter SR, Kitchell JF (1999) Trophic cascades revealed in diverse ecosystems. Trends Ecol Evol 14:483-488

Pauly D, Christensen V, Dalsgaard J, Froese R, Torres F Jr (1998) Fishing down marine food webs. Science 297:860-863

Pinheiro J, Bates D, DebRoy S, Sarkar D, R Core Team (2016) nlme: Linear and Nonlinear Mixed Effects Models. R package version 3.1-125. http://CRAN.R-project.org/package=nlme

Polis GA, Anderson WB, Holt RD (1997) Toward an integration of landscape and food web ecology: the dynamics of spatially subsidized food webs. Annu Rev Ecol Syst 28:289-316 
Polis GA, Sears ALW, Huxel GR, Strong DR, Maron J (2000) When is a trophic cascade a trophic cascade? Trends Ecol Evol $15: 473-475$

Polis GA, Strong DR (1996) Food web complexity and community dynamics. Am Nat 147:813-846

R Development Core Team (2016) R: A language and environment for statistical computing. R Foundation for Statistical Computing, Vienna, Austria. ISBN 3-900051-07-0. http://www.R-project.org/

Randall JE, Head SM, Sanders APL (1978) Food habits of the giant humphead wrasse, Cheilinus undulatus (Labridae). Environ Biol Fish 3:235-238

Rasher DB, Hoey AS, Hay ME (2013) Consumer diversity interacts with prey defenses to drive ecosystem function. Ecology 94:1347-1358

Ripple WJ, Larsen EJ, Renkin RA, Smith DW (2001) Trophic cascades among wolves, elk and aspen on Yellowstone National Park's northern range. Biol Conserv 102:227-234

Ritchie EG, Johnson CN (2009) Predator interactions, mesopredator release and biodiversity conservation. Ecol Lett 12:982-998

Rizzari JR, Bergseth BJ, Frisch AJ (2015) Impact of conservation areas on trophic interactions between apex predators and herbivores on coral reefs. Conserv Biol 29:418-429

Robbins WD, Hisano M, Connolly SR, Choat JH (2006) Ongoing collapse of coral-reef shark populations. Curr Biol 16:2314-2319

Roff G, Doropoulos C, Rogers A, Bozec Y-M, Krueck NC, Aurellado E, Priest M, Birrell C, Mumby PJ (2016) The ecological role of sharks on coral reefs. Trends Ecol Evol 31:395-407

Ruppert JLW, Travers MJ, Smith LL, Fortin M-J, Meekan MG (2013) Caught in the middle: combined impacts of shark removal on the fish communities of coral reefs. PLoS One 8:e74648

Russ GR, Cheal AJ, Dolman AM, Emslie MJ, Evans RD, Miller I, Sweatman H, Williamson DH (2008) Rapid increase in fish numbers follows creation of the world's largest marine reserve network. Curr Biol 18:R514-R515

Salomon AK, Gaichas SK, Shears NT, Smith JE, Madin EMP, Gaines SD (2010) Key features and context-dependence of fisheryinduced trophic cascades. Conserv Biol 24:1523-1739

Sandin SA, Smith JE, DeMartini EE, Dinsdale EA, Donner SD, Friedlander AM, Konotchick T, Malay M, Maragos JE, Obura D, Pantos O, Paulay G, Richie M, Rohwer F, Schroeder RE, Walsh S, Jackson JBC, Knowlton N, Sala E (2008) Baselines and degradation of coral reefs in the Northern Line Islands. PLoS One 3:e1548

Scharf FS, Juanes F, Rountree RA (2000) Predator size-prey size relationships of marine fish predators: interspecific variation and effects of ontogeny and body size on trophic niche breadth. Mar Ecol Prog Ser 208:229-248
Shipley B (2009) Confirmatory path analysis in a generalized multilevel context. Ecology 90:363-368

Shurin JB, Borer ET, Seabloom EW, Anderson K, Blanchette CA, Broitman B, Cooper SD, Halpern BS (2002) A cross-ecosystem comparison of the strength of trophic cascades. Ecol Lett 5:785-791

Shurin JB, Seabloom EW (2005) The strength of trophic cascades across ecosystems: predictions from allometry and energetics. $\mathrm{J}$ Anim Ecol 74:1029-1038

Stier AC, Hein AM, Parravicini V, Kulbicki M (2014) Larval dispersal drives trophic structure across Pacific coral reefs. Nature Commun 5:1-6

Strong D (1992) Are trophic cascades all wet? Differentiation and donor-control in speciose ecosystems. Ecology 73:747-754

Sweatman H, DeLean S, Syms C (2011) Assessing loss of coral cover on Australia's Great Barrier Reef over two decades, with implications for longer-term trends. Coral Reefs 30:521-531

Taylor BM (2014) Drivers of protogynous sex change differ across spatial scales. Proc R Soc B 281:20132423

Taylor S, Webley J, McInnes K (2012) 2010 statewide recreational fishing survey. State of Queensland, Department of Agriculture, Fisheries and Forestry

Thompson RM, Hemberg M, Starzomski BM, Shurin JB (2007) Trophic levels and trophic tangles: the prevalence of omnivory in real food webs. Ecology 88:612-617

Venables WN, Ripley BD (2002) Modern statistics with S, 4th edn. Springer, New York

Vermeij MJA, DeBey H, Grimsditch G, Brown J, Obura D, DeLeon R, Sandin SA (2015) The negative effect of gardening damselfish (Stegastes planifrons) on coral health depends on predator abundance in a Caribbean MPA. Mar Ecol Prog Ser 528:289-296

Wetherbee BM, Crow GL, Lowe CG (1997) Distribution, reproduction and diet of the gray reef shark Carcharhinus amblyrhynchos in Hawaii. Mar Ecol Prog Ser 151:181-189

Williams ID, Baum JK, Heenan A, Hanson KM, Nadon MO, Brainard RE (2015b) Human, oceanographic and habitat drivers of central and western Pacific coral reef fish assemblages. PLoS One 10:e0120516

Williams GJ, Gove JM, Eynaud Y, Zgliczynski BJ, Sandin SA (2015a) Local human impacts decouple natural biophysical relationships on Pacific coral reefs. Ecography 38:751-761

Wilson SK, Fisher R, Pratchett MS, Graham NAJ, Dulvy NK, Turner RA, Cakacaka A, Polunin NVC, Rushton SP (2008) Exploitation and habitat degradation as agents of change within coral reef fish communities Glob Change Biol 14:2796-2809 